\title{
The impact of probable anxiety and mood disorder on self-reported collisions: A population study
}

\author{
Wickens, C. M., Mann, R. E., Stoduto, G., Ialomiteanu, A., \\ Smart, R. G., \& Rehm, J.
}

Version Post-Print/Accepted Manuscript

Citation Wickens, C. M., Mann, R. E., Stoduto, G., Ialomiteanu, A., Smart, R. (published version) G., \& Rehm, J. (2013). The impact of probable anxiety and mood disorder on self-reported collisions: A population study. Journal of Affective Disorders, 145, 253-255.

\section{Copyright / License (c) (i)}

This work is licensed under a Creative Commons AttributionNonCommercial-NoDerivatives 4.0 International License.

Publisher's Statement The final publication is available at Elsevier via http://dx.doi.org/10.1016/j.jad.2012.04.046.

Always cite the published version, so the author(s) will receive recognition through services that track citation counts, e.g. Scopus. If you need to cite the page number of the TSpace version (original manuscript or accepted manuscript) because you cannot access the published version, then cite the TSpace version in addition to the published version using the permanent URI (handle) found on the record page. 
Running head: ANXIETY AND MOOD DISORDER AND COLLISIONS

\title{
The Impact of Probable Anxiety and Mood Disorder on Self-Reported Collisions:
} A Population Study

\author{
Christine M. Wickens ${ }^{1}$, Robert E. Mann ${ }^{1,2}$, Gina Stoduto ${ }^{1}$, Anca Ialomiteanu ${ }^{1}$, \\ Reginald G. Smart ${ }^{1}$, \& Jürgen Rehm ${ }^{1,2,3}$ \\ 1 - Centre for Addiction and Mental Health, Toronto, Ontario, Canada \\ 2 - Dalla Lana School of Public Health, University of Toronto, Toronto, Ontario, Canada \\ 3 - Department of Psychiatry, Faculty of Medicine, University of Toronto, \\ Toronto, Ontario, Canada
}

Correspondence concerning this article should be addressed to:

Dr. Christine M. Wickens

Centre for Addiction and Mental Health

Social and Epidemiological Research Department

33 Russell Street, T417

Toronto, Ontario M5S 2S1

Canada

Email: christine_wickens@camh.net

Telephone: (416) 535-8501 ext. 4711

Fax: (416) 595-6899 


\begin{abstract}
Background. Individuals diagnosed with psychiatric disorder are at significantly increased risk of death and serious injury, to which motor vehicle collisions may be important contributors. This study examined the association between probable anxiety or mood disorder (AMD) and self-reported collision risk in a large representative sample of the adult population in Ontario. Methods. Based on data from a regionally stratified general-population telephone survey of adults conducted from 2002 through $2009(N=12,830)$, a logistic regression analysis examined self-reported collision involvement in the previous 12 months by measures of demographic characteristics, driving exposure, impaired driving behaviour, and probable AMD.

Results. Controlling for demographic variables and potential confounders, probable AMD was associated with an increased risk of collision involvement $(\mathrm{OR}=1.78,95 \% \mathrm{CI}=1.37,2.31)$.

Limitations. The use of self-report measures and the potential for bias created by groups excluded because they do not have access to landline telephones represent limitations to the current findings. Nevertheless, the benefits of a large sample derived from general population survey data far outweigh these limitations.

Conclusions. The results suggest that the increased risk of injury and mortality associated with some psychiatric disorders is at least partially related to increased risk of collision involvement. The magnitude of the increase in risk associated with probable AMD is similar to that seen among individuals who drive after drinking or using cannabis. In view of these findings, more work to understand this risk among individuals experiencing probable AMD and how it can be avoided is necessary.
\end{abstract}

Keywords: Anxiety disorder, mood disorder, collisions 


\section{The Impact of Probable Anxiety and Mood Disorder on Collision Risk}

\section{Introduction}

Mortality rates among those diagnosed with a psychiatric disorder may be increased four times or more and life expectancy is substantially reduced (Grigoletti et al., 2009; Thornicroft, 2011). A leading contributor to premature mortality is involvement in motor vehicle collisions (MVCs), which may be affected by some psychiatric conditions (Grigoletti et al., 2009; Dumais et al., 2005). Anxiety and mood disorders (AMD) are among the most common psychiatric disorders (Kessler \& Wang, 2008) and, along with some of the drugs used to treat them, may affect driving-related skills adversely (Hindmarch et al., 1992; Vingilis and Wilk, 2012). However, the available evidence on the association of AMD with collision risk is mixed (Dumais et al., 2005; Sagberg, 2006; Selzer et al., 1968; Vingilis and Wilk, 2012). Several explanations for these inconsistent results are possible. Many studies are older and involve restricted sample sizes (e.g., Selzer et al., 1968). As well, available studies do not control for the effects of confounders or covariates that could account for an observed association between AMD and collision risk. One very important class of potential confounding measures is substance use. AMD is frequently comorbid with substance abuse or dependence (Kessler \& Wang, 2008), and the increased collision risk associated with AMD seen in some studies may instead be due to higher rates of driving after drinking or after using cannabis among individuals experiencing these disorders. In this study we assess the association of past year collision involvement with probable AMD while controlling for the effects of demographic measures, driving exposure, and driving after using alcohol and cannabis in a large representative sample of the adult population. 


\section{Method}

\subsection{Sample}

Data are based on telephone interviews with 12,830 respondents who reported having driven a vehicle in the past year, derived from the 2002-2009 cycles of the Centre for Addiction and Mental Health (CAMH) Monitor, an ongoing cross-sectional survey of adults in Ontario, Canada aged 18 years and older that employs random-digit-dialling methods via Computer Assisted Telephone Interviewing. Each annual cycle consists of 12 independent monthly samples with approximately 200 completions each. The annual response rates range from $53 \%$ to $61 \%$ (see Ialomiteanu and Adlaf, 2010 for sampling design details). Institutional research ethics committees at CAMH have approved the survey annually.

\subsection{Variables}

The key outcome measure was involvement in a MVC in the past 12 months (coded no=0, yes $=1$ ). Demographic variables included age, gender, region of residence, income and marital status. Weekly driving distance, included as a control for differences in exposure, was treated as a continuous variable. Impaired driving measures included past-year driving after drinking (driving one or more times after having two or more drinks in the previous hour: coded $0=$ no, $1=$ yes) and driving after cannabis use (driving one or more times within an hour of using cannabis, marijuana or hash: coded $0=$ no, $1=$ yes $)$.

The General Health Questionnaire was originally developed as a screening instrument for detecting non-psychotic mental illness, and a 12-item version (GHQ12) that focuses on indicators of depression and anxiety has been widely validated in general population samples. In survey samples of adults (Bijl et al., 1998; Mann et al., 2011a) and adolescents (Mann et al., 2011b) the GHQ12 performed well in identifying probable AMD. Among Ontario adults (Mann 
et al., 2011a), the AUC value was .89 and a cutoff value of 4 appeared optimal for detecting probable AMD. At this level the estimated prevalence of probable AMD in the population overall, and in males and females separately, were nearly identical to those obtained using the Composite International Diagnostic Interview (Rush et al., 2008). We use the term 'probable AMD' to distinguish between this measure and AMD cases that would be identified by a more formal diagnostic process. For this research we used the binary scoring system for the GHQ12. The Likert responses for each item were recoded to "0-0-1-1", where 1 represents a response indicating somewhat or a lot more than usual experience of a depression or anxiety symptom, and a score of 4 or more indicated probable AMD (Mann et al., 2011a).

\subsection{Analyses}

We employed design-based analyses using Taylor Series Linearization found in STATA11 software. Thus, all estimates and statistical tests were corrected for the sampling design. The weighted sample size was used when reporting percentages, and these are considered representative of the population surveyed. Item missing data (i.e. "don't know" responses and refusals) were excluded listwise from all analyses.

\section{Results}

Table 1 presents self-reported MVC involvement by demographic characteristics, driving exposure, impaired driving, and evidence of AMD. The overall prevalence of MVC involvement was 7.6\%. Based on chi-square (svy: tab) and linear regression (svy: reg) analyses, with $p$-values evaluated from the design-based $F$ statistic, MVC involvement was higher for males, drivers aged 18-34 years, drivers who at least completed high school and who earned higher incomes, and drivers who had never been married. Motorists who reported involvement in a MVC also reported a greater number of kilometres driven weekly than motorists not involved in a MVC. 
Likewise, motorists who reported driving after drinking or driving after cannabis use were also more likely to report MVC involvement. Finally, reporting a MVC was significantly more likely among drivers identified with probable AMD.

We then conducted a binary logistic regression analysis (svy: logit) (Lee \& Forthofer, 2006) of the relationship between AMD and collision risk while controlling for the potentially confounding influences of gender, age, region, income, marital status, driving exposure, driving after drinking, and driving after cannabis use. Before the logistic regression model was conducted, markers for multicollinearity were assessed (Field, 2005) and were indicative of an absence of multicollinearity. The $F$-adjusted mean residual goodness-of-fit test for the final model was not significant, indicating good fit. The odds of self-reported collision involvement for those classified with probable $A M D$ was nearly doubled $(\mathrm{OR}=1.78,95 \% \mathrm{CI}=1.37,2.31$, $p<.001)$ after controlling for potential confounders.

\section{Discussion}

Both univariate and multivariate analyses showed that probable AMD in a large representative adult population sample was associated with significantly higher odds of past-year collision involvement. This increase is observed even after controlling for demographic factors, driving exposure, and driving after alcohol and cannabis use. Probable AMD was found to nearly double the risk of a past-year MVC. This finding supports other recent studies suggesting that AMD is associated with increased collision risk (Sagberg, 2006; Selzer et al., 1968) and suggests that the results of other studies are not simply due to the confounding effects of demographic factors, differential driving exposure or increased driving after alcohol or cannabis use. The increased risk of collision involvement associated with probable AMD is comparable to that seen with driving after drinking or cannabis use. 
There are several possible reasons for this relationship between AMD and collision risk. Anxious and depressed drivers exhibit driving skills deficits that result in the commission of more driving errors (Ramaekers et al., 1997; Stephens \& Groeger, 2009). Both anxiety and depression have been found to intensify aggressive responses to frustrating roadway events ( $\mathrm{Yu}$ et al., 2004). These conditions, and some of the drugs used to treat them, have been associated with cognitive and psychomotor disturbances that can affect driving skills (Hindmarch et al., 1992; Taylor et al., 2008). More research is needed to understand why these effects occur, and how they may be alleviated.

The limitations of this study include use of self-report measures and the potential for bias created by groups excluded because they do not have access to landline telephones.

Nevertheless, based on a large sample derived from general population survey data, the current study suggests that for patients with AMD, increased mortality rates and reduced life expectancy may result in part from increased likelihood of MVC involvement. The magnitude of the increase in collision risk seen was comparable to that seen for driving after substance use. 


\section{References}

Bijl, R.V., Van Zessen, G., Ravelli, A., De Rilk, C., Langendoen, Y., 1998. The Netherlands Mental Health Survey and Incidence Study (NEMESIS): objectives and design. Soc. Psych. Psych. Epid. 33, 581-6.

Dumais, A., Lesage, A.D., Boyer, R., Lalovic, A., Chawky, N., Ménard-Buteau, C., et al., 2005. Psychiatric risk factors for motor vehicle fatalities in young men. Can. J. Psychiat. 50, 838-44.

Field, A., 2005. Discovering statistics using SPSS. SAGE Publications, Inc., Thousand Oaks, CA.

Grigoletti, L., Perini, G., Rossi, A., Biggeri, A., Barbui, C., Tansella, M., Amaddeo, F., 2009. Mortality and cause of death among psychiatric patients: a 20-year case-register study in an area with a community-based system of care. Psychol. Med. 39, 1875-84.

Hindmarch, I., Alford, C., Barwell, F., Kerr, J.S., 1992. Measuring the side effects of psychotropics: The behavioural toxicity of antidepressants. J. Psychopharmacol. 6, 198203.

Ialomiteanu, A., Adlaf, E.M., 2010. CAMH Monitor 2009: Technical Guide. Centre for Addiction and Mental Health, Toronto, Canada.

Kessler, R.C., Wang, P.S., 2008. The descriptive epidemiology of commonly occurring mental disorders in the United States. Annu. Rev. Publ. Health. 29, 115-29.

Lee, E.S., Forthofer, R.N., 2006. Analyzing complex survey data ( $2^{\text {nd }}$ ed.). Sage Publications, INC., 2006. Downloaded 2011, August 23 from http://www.sagepub.com/upmdata/6428_Chapter_6_Lee_(Analyzing)_I_PDF_7.pdf

Mann, R.E., Cheung, J.T.W., Ialomiteanu, A., Stoduto, G., Chan, V., Wickens, C.M., et al., 
2011a. Estimating prevalence of anxiety and mood disorder in survey data using the GHQ12: Exploration of threshold values. Eur. J. Psychiat. 25, 81-91.

Mann, R.E., Paglia-Boak, A., Adlaf, E.M., Beitchman, J., Wolfe, D., Wekerle, C., et al., $2011 b$. Estimating the prevalence of mood and/or anxiety disorder in an adolescent general population: An evaluation of the General Health Questionnaire. Int. J. Ment. Health Addiction 9, 410-420.

Ramaekers, J.G., Ansseau, M., Muntjewerff, N.D., Sweens, J.P., O’Hanlon, J.F., 1997. Considering the P450 cytochrome system as determining combined effects of antidepressants and benzodiazepines on actual driving performance of depressed outpatients. Int. Clin. Psychopharm. 12, 159-69.

Rush, B.R., Urbanoski, K., Bassani, D., Castel, S., Wild, T.C., Strike, C., et al., 2008. Prevalence of co-occurring substance use and other mental disorders in the Canadian population. Can. J. Psychiat. 53, 800-9.

Sagberg, F., 2006. Driver health and crash involvement: A case-control study. Accident Anal. Prev. 38, 28-34.

Selzer, M.L., Rogers, J.E., Kern, S., 1968. Fatal accidents: The role of psychopathology, social stress, and acute disturbance. Am. J. Psychiat. 124, 1028-36.

Stephens, A.N., Groeger, J.A., 2009. Situational specificity of trait influences on drivers' evaluations and driving behaviour. Transport. Res. F-Traf. 12, 29-39.

Taylor, J.E., Deane, F.P., Podd, J., 2008. The relationship between driving anxiety and driving skill: A review of human factors and anxiety-performance theories to clarify future research needs. New Zeal. J. Psychol. 37, 28-37.

Thornicroft, G., 2011. Physical health disparities and mental illness: the scandal of premature 
mortality. Brit. J. Psychiat. 199, 441-2.

Vingilis, E., Wilk, P., 2012. Medical conditions, medication use and their relationship with subsequent motor vehicle injuries: Examination of the Canadian National Population Health Survey. Traffic Inj. Prev. 13, 327-36.

Yu, J., Evans, P.C., Perfetti, L., 2004. Road aggression among drinking drivers: Alcohol and non-alcohol effects on aggressive driving and road rage. J. Crim. Just. 32, 421-30. 


\section{TABLE 1}

Self-reported past year MVC involvement by demographics, driving exposure, impaired driving, and probable AMD: Ontario CAMH Monitor, 2002 - 2009.

\begin{tabular}{|c|c|c|}
\hline & $n$ & $\begin{array}{c}\mathrm{MVC}^{\mathrm{a}} \\
\% \mathrm{Yes}^{\mathrm{b}}\left(95 \% \mathrm{CI}^{\mathrm{c}}\right)\end{array}$ \\
\hline TOTAL $^{\mathrm{d}}$ & 12830 & $7.6(7.0,8.2)$ \\
\hline \multicolumn{3}{|l|}{ DEMOGRAPHIC VARIABLES: } \\
\hline Gender & & $*$ \\
\hline Female & 6950 & $6.8(6.1,7.6)$ \\
\hline Male & 5880 & $8.3(7.5,9.2)$ \\
\hline Age & & $* * *$ \\
\hline 18-34 years & 2630 & $11.1(9.7,12.7)$ \\
\hline $35-54$ years & 5531 & $6.7(6.0,7.5)$ \\
\hline $55+$ years & 4394 & $5.5(4.7,6.4)$ \\
\hline \multicolumn{3}{|l|}{ Region } \\
\hline Toronto & 1796 & $8.4(7.1,10.0)$ \\
\hline Central East & 2168 & $7.9(6.6,9.4)$ \\
\hline Central West & 2135 & $8.2(7.0,9.6)$ \\
\hline West & 2263 & $6.4(5.3,7.6)$ \\
\hline East & 2147 & $7.1(5.9,8.4)$ \\
\hline North & 2321 & $5.6(4.6,6.7)$ \\
\hline Income $^{\mathrm{e}}$ & & $* * *$ \\
\hline$<\$ 30,000$ & 1545 & $6.8(5.3,8.6)$ \\
\hline$\$ 30,000-49,999$ & 2014 & $7.6(6.2,9.2)$ \\
\hline$\$ 50,000-79,999$ & 2807 & $8.2(7.0,9.5)$ \\
\hline$\$ 80,000+$ & 4058 & $8.7(7.7,9.8)$ \\
\hline Not stated & 2406 & $5.1(4.1,6.3)$ \\
\hline Marital Status & & $* * *$ \\
\hline Married/partner & 8257 & $6.3(5.8,7.0)$ \\
\hline Previously married & 2317 & $7.7(6.3,9.2)$ \\
\hline Never married & 2149 & $11.7(10.1,13.6)$ \\
\hline \multicolumn{3}{|l|}{ DRIVING EXPOSURE: } \\
\hline Km driven-typical week $(100 s)^{f}$ & & $* * *$ \\
\hline mean $\left(\mathrm{SD} ; 95 \% \mathrm{CI}^{\mathrm{c}}\right) \mathrm{MVC}^{\mathrm{a}}$ No & 11004 & $3.05(5.15 ; 2.92,3.17)$ \\
\hline MVC $^{\mathrm{a}}$ Yes & 802 & $3.86(5.55 ; 3.41,4.31)$ \\
\hline \multicolumn{3}{|c|}{ IMPAIRED DRIVING VARIABLES: } \\
\hline Driving after drinking $^{\mathrm{a}}$ & & $* * *$ \\
\hline No & 11830 & $7.2(6.6,7.8)$ \\
\hline Yes & 897 & $11.8(9.3,14.9)$ \\
\hline Driving after cannabis use $\mathrm{a}^{\mathrm{a}}$ & & $* * *$ \\
\hline
\end{tabular}


No

Yes

PROBABLE AMD:

$* * *$

No

Yes

${ }^{\mathrm{a}}$ In the last 12 months.

${ }^{\mathrm{b}}$ Percentages reported are based on weighted sample size.

${ }^{\mathrm{c}}$ Confidence intervals.

${ }^{\mathrm{d}}$ Respondents who report having driven a motor vehicle in the last 12 months.

${ }^{\mathrm{e}}$ Canadian dollars.

${ }^{\mathrm{f}}$ Driving distance was divided by 100 so that the resulting odds ratio reflected the change in risk for each additional 100 kilometres of weekly driving.

Design-based $F$ statistical significance $* p<.05 ; * * p<.01 ; * * * p<.001$ 